\title{
Development and sizing of a grid-connected solar PV power plant for Canaanland community
}

\author{
Adeyemi A. Alabi, Anthony U. Adoghe, Oluwasikemi G. Ogunleye, Claudius O.A Awosope \\ Department of Electrical and Informatiion Engineering, Covenant University, Nigeria
}

\begin{tabular}{l}
\hline Article Info \\
\hline Article history: \\
Received Oct 9, 2018 \\
Revised Dec 14, 2018 \\
Accepted Dec 31, 2018 \\
\hline Keywords: \\
Energy consumption \\
Load profile \\
Mini-grid \\
PVsysts \\
Solar photovoltaic
\end{tabular}

Article Info

rticle history:

Received Oct 9, 2018

Revised Dec 14, 2018

Keywords

Energy consumption

Mini-grid

Solar photovoltaic

\begin{abstract}
High costs of installation and maintenance as a result of storage units discourage the use of solar Photovoltaic system for power generation. To reduce these costs, Solar PV systems can be installed without storage units alongside conventional power generation systems. Such that the Solar systems cater for the daytime loads while the conventional generation system caters for loads at other times. This research paper explored the potential of installing Stand-Alone solar PV systems without storage to satisfy the daytime load demand of the Canaanland community. The load profile analysis of the Canaanland community was carried out from load consumption data and the solar power plants were designed based on this analysis. Simulation was carried out using the PV Syst 6.43 software and the result from the design was analyzed. The study revealed that the solar power plant will serve the daytime load of the community during the period of $10: 30 \mathrm{am}-4: 30 \mathrm{pm}$ daily satisfying the peak and base loads $(5.16 \mathrm{MW}$ and $0.78 \mathrm{MW}$ ) of the Canaanland community respectively.
\end{abstract}

Copyright $\odot 2019$ Institute of Advanced Engineering and Science. All rights reserved.

\section{Corresponding Author:}

Adeyemi A. Alabi,

Department of Electrical and Informatiion Engineering,

Covenant University, Ota, Nigeria.

Email: adeyemi.alabi@stu.cu.edu.ng

\section{INTRODUCTION}

Electricity is an important element for social, educational, economic and political development of every nation. Energy plays a cogent role in the growth, and development of the economy, poverty eradication and security of any nation [1]. In a bid to improve electricity generation and supply in Nigeria, the Federal government unbundled of the former National Electricity Power Authority (NEPA) in 2005 and the encouraged private sector participation in the electricity industry[2]. In 2013, the privatization approach took a different shape as licenses were given to private companies to either generate or distribute electricity across different parts of the country[2]. Unfortunately, these actions implemented by successive governments have not made the situation any better. The electricity reform agenda of government is yet to be felt in terms of steady power supply for both residential and commercial user of electricity. Power outage remains one of the main challenges facing the residential, commercial and industrial sectors of the Nigeria economy and all attempts at addressing this problem have not yielded the desired results[2]. Large institutions, such as universities, consume large amounts of energy daily and because of their peculiar nature as knowledge-based institutions, the source of energy predominantly in use in the universities and other tertiary institutions for educational activities is electricity [3]. As a result, universities and other academic institutions in Nigeria make great efforts to compliment the unsteady electricity supply from the national grid with diesel generators which are most often run at a very high financial and environmental cost to the management of such Institutions. The negative impact of this is the releasing of vast amount of unhealthy carbon waste into the atmosphere. It is pertinent that greener energy such as energy from the sun is explored as an alternative to the fossil fuel-based conventional power generating system mostly used in developing countries. 
The issues of electric energy availability, consumption and costs in universities with resident students and staff quarters can present a formidable challenge to any responsible university administration. This is because its availability or otherwise can have profound effects not only on academic activities but also on the social and economic activities in the system [4]. Additional infrastructure, financial constraints, increase energy demand, frequent outages and environmental awareness are motivating factors for university communities to re-evaluate their energy generation systems. The availability of an economically viable, clean and reliable power supply for an academic community will improve the overall productivity of the community by; enhancing research, powering teaching aids and equipment for a conducive learning environment.

Nigeria, being on the equator, receives an average solar radiation varying from about $12.6 \mathrm{MJ} / \mathrm{m}^{2}$ day in the coastal latitudes to about $25.2 \mathrm{MJ} / \mathrm{m}^{2}$-day in the far North [5]. This makes harnessing energy from the sun to generate electricity a very viable alternative to the epileptic supply from the national grid. Sunshine intensity in Ota located in the south-western part of Nigeria, can produce as much as $4.55 \mathrm{kWh} / \mathrm{m}^{2}$ daily sunshine [5]. Studies have shown that the months of February and November records the highest solar radiation due to the high level of sunshine during these periods. While July and August are the months with the least solar radiation due to heavy rainfall that characterized these months in this area [5], [6].

In this research work, stand-alone solar pv power plants was designed to satisfy the daytime load demand of Canaanland community. The Stand-alone solar plant will connect and complement the existing gas/diesel turbine power generation system in the community during the day. This project begins with a review of previous literature where information on the derived solar insolation of the location is obtained for the estimation of yield. The existing power generation system of the community is then studied to determine its availability probability. Following this, an extensive load profiling of the Canaanland community is studied with a view to identifying the base and peak loads, daytime and nighttime loads, the peak and offpeak seasons, the peak day and off-peak days. Based on this, a stand-alone solar power plant is designed to supply the daytime loads of the community with the aim of reducing the run time of the installed gas/diesel turbine thereby lowering the cost by reducing fuel consumption and lowering carbon emission while meeting the daytime load demand of the community

In [7], a public lecture at the Covenant University was given emphasizing the relevance of solar energy in the modern-day power generation viewing it as a friendly renewable energy option for Nigeria. It was mentioned that Energy is one of the main factors responsible for disparity and widening of "developmental gap" among the developed, developing and the underdeveloped nations of the world. The work further explained the fundamentals of solar radiation, factors affecting global solar radiation, solar energy applications, and solar conversion applications taking solar electrification of a particular compound in Lagos State as a case study. However, apart from the brief market survey of certain solar products, there was no assessment of the solar radiation data for the location. Also, there was no systematic modeling for the performance of the system.

A performance assessment on a 3-MW scale grid-connected solar photovoltaic power plant at Kolar, India [8] revealed some technical issues such as low yield due to the teething trouble associated with inverters and the grid as a result of grid and interconnection disturbances. The impact of temperature on the performance of the photovoltaic mono-crystalline silicon modules was also studied and it was observed that the modules are more sensitive to temperature than solar insolation. [8] observed that the efficiency of the modules drops from $14.5 \%$ to $11.5 \%$ corresponding to temperature rise from $25^{\circ} \mathrm{C}$ to $50^{\circ} \mathrm{C}$. [8] recommended cooling of modules in order to achieve higher yield, but there was no comparative study with other technologies on issues of space required for yield at the prevailing condition.

\section{RESEARCH METHOD}

\subsection{Daytime load profile of the community}

The power demanded for every hour by the community was recorded on the hour for the years 2016 and 2017 giving a data set of $731 \times 24$. This data was then computed using Matrix Laboratory (MATLAB) Software to determine the daytime load profile of the community taken to be the period between 7am and $7 \mathrm{pm}$ for this research. The results were presented in Table 1. It was observed that the peak hourly demands for Covenant University and Missions were $2.55 \mathrm{MW}$ and $3.98 \mathrm{MW}$ respectively, while the average power demand ranged between $0.78 \mathrm{MW}$ and $0.89 \mathrm{MW}$ for Covenant University and $0.79 \mathrm{MW}$ and $1.16 \mathrm{MW}$ for Mission.

Int J Appl Power Eng, Vol. 8, No. 1, April 2019: 69-77 
Table 1. Daytime Load Power Demand from 7am -7pm

\begin{tabular}{lcccccc}
\hline & \multicolumn{3}{c}{ Average Power (MW) } & \multicolumn{3}{c}{ Peak Power (MW) } \\
\cline { 2 - 7 } & CU & Misison & Canaanland & CU & Misison & Canaanland \\
\hline 7am & 0.78 & 0.79 & 1.61 & 1.91 & 2.92 & 4.83 \\
$8 \mathrm{am}$ & 0.83 & 0.91 & 1.77 & 2.03 & 3.06 & 5.03 \\
9am & 0.88 & 1.04 & 1.96 & 2.42 & 3.4 & 5.17 \\
$10 \mathrm{am}$ & 0.89 & 1.12 & 2.05 & 2.42 & 3.78 & 4.5 \\
$11 \mathrm{am}$ & 0.88 & 1.16 & 2.10 & 2.54 & 3.98 & 4.54 \\
$12 \mathrm{am}$ & 0.86 & 1.13 & 2.02 & 2.55 & 3.68 & 4.75 \\
$1 \mathrm{pm}$ & 0.85 & 1.15 & 2.07 & 2.4 & 3.68 & 4.8 \\
$2 \mathrm{pm}$ & 0.84 & 1.14 & 2.02 & 2.4 & 3.68 & 4.78 \\
$3 \mathrm{pm}$ & 0.82 & 1.06 & 1.93 & 2.52 & 3.6 & 4.61 \\
$4 \mathrm{pm}$ & 0.81 & 1.05 & 1.89 & 2.39 & 3.52 & 4.54 \\
$5 \mathrm{pm}$ & 0.80 & 0.98 & 1.84 & 2.42 & 3.58 & 4.43 \\
$6 \mathrm{pm}$ & 0.79 & 0.88 & 1.71 & 2.15 & 3.08 & 3.59 \\
$7 \mathrm{pm}$ & 0.89 & 0.86 & 1.80 & 2.13 & 3.2 & 4.5 \\
Peak & 0.89 & 1.16 & 2.10 & 2.55 & 3.98 & 5.17 \\
\hline
\end{tabular}

\subsection{Determining the plant size}

The plant is intended to supply only the daytime (7am-7pm) load of the community, the size of the plant is then determined by the daytime load demand of the community. Since the PV system is to be designed to complement the existing power generation system in the community, it is expected to work in synchronization with the newly installed 5 generators rated 1.2-MW each and 5.67-MW turbine in the community. When the power demanded is predicted to be more than what the solar PV system generates, the least unit of the gas generator kicks on and adds to the supply. The ultimate target of the solar plant is to supply most of the average daytime load of the community, and to ensure that there is enough reserve margin to accommodate potential growth in load demand and unforeseen load variation, the power plant sizes for Covenant University and Missions were sized and determined to be 3MW and 4.8MW respectively using (1) [8]. This gives a leeway of $20 \%$ reserve for the daytime peak demand for Covenant University and Missions. When combined, the power plants give a total of $7.8 \mathrm{MW}$ for the Canaanland Community whose daytime peak load is $5.17 \mathrm{MWleaving}$ a lee-way of $33 \%$ reserve.

$P_{S}=P_{L} * 1.2$

where:

$P_{S}=$ Plant size

$P_{L}=$ Peak load

\subsection{Determining the plant size}

To determine the optimal inclination angle for PV installation at Canaanland, Satellite data from Online repository of the European Commission's Photovoltaic Geographical Information System was used. Geographical coordinates of the area under study were imputed to the platform to generate the radiation data required to calculate the optimal inclination angle for installation. Climate-SAF PVGIS Data was selected as the preferred data for this work. The optimal inclination angle was gotten to be $11^{0}$ and the radiation at the optimal inclination, as compared to on a plane as well as at an inclination angle of $90^{\circ}$ for each month, is presented in Table 2.

\subsection{Selection and sizing of solar PV module}

In selecting the PV module to be used for the design, comparison was made among three different solar technologies discussed in chapter 2. Mono Crystalline Silicon technology was selected based on efficiency and area per kWp to be the preferred solar pv module for the design in this work. The minimum sizes of the PV array for the proposed 3-MW and 4.8-MW Solar PV power plants are determined using (2) and (3) [9].

$P_{\text {Array }}=\frac{E_{l}}{P_{\text {sun }} \times \eta_{\text {system }}}$

where:

$p_{\text {Array }}=$ Peak wattage of the array in $\left(\mathrm{W}_{\mathrm{p}}\right)$;

$P_{\text {sun }}=$ peak sun hours at design tilt for location, taken as 4 hours for this study, and 
The overall system efficiency is a function of the efficiency of the Maximum power point tracking, distribution cable efficiency, optimizer efficiency, and the inverter efficiency.

$\eta_{\text {system }}=\eta_{M P P T} \times \eta_{\text {dist }} \times \eta_{\text {opt }} \times \eta_{\text {inv }}$

$\eta_{\text {system }}=$ overall system efficiency

$\eta_{M P P T}=1 \%$ loss in maximum power point tracking (MPPT) operation mode, hence 0.99

$\eta_{\text {dist }}=7 \%$ losses in distribution cables from battery to loads, hence 0.93

$\eta_{\text {opt }}=5 \%$ losses in the optimizer, hence 0.95 , and

$\eta_{\text {inv }}=$ efficiency of inverter.

Table 2. Annual Irradiation at Canaanland Community

\begin{tabular}{|c|c|c|c|c|}
\hline Month & Hh (Wh/m2/day) & $\mathrm{H}(11)(\mathrm{Wh} / \mathrm{m} 2 /$ day $)$ & $\mathrm{H}(90)(\mathrm{Wh} / \mathrm{m} 2 /$ day $)$ & Iopt (deg) \\
\hline Jan & 5,780 & 6,260 & 4,260 & 35 \\
\hline Feb & 5,750 & 6,010 & 3,300 & 24 \\
\hline Mar & 6,050 & 6,100 & 2,470 & 9 \\
\hline Apr & 5,610 & 5,450 & 1,000 & -7 \\
\hline May & 5,110 & 4,840 & 981 & -19 \\
\hline Jun & 4,190 & 3,960 & 998 & -22 \\
\hline Jul & 4,030 & 3,850 & 1,100 & -18 \\
\hline Aug & 4,160 & 4,040 & 1,140 & -10 \\
\hline Sep & 4,300 & 4,280 & 1,670 & 3 \\
\hline Oct & 4,570 & 4,680 & 2,380 & 17 \\
\hline Nov & 5,160 & 5,500 & 3,490 & 30 \\
\hline Dec & 5,520 & 6,030 & 4,330 & 37 \\
\hline Yearly Average & 5,010 & 5,080 & 2,260 & 11 \\
\hline $\begin{array}{l}\text { Latitude: } 6^{\circ} 40^{\prime} 18 \\
\text { Annual irradiatio } \\
\text { Hh: Irradiation or } \\
\text { H(11): Irradiation } \\
\text { H(90): Irradiation } \\
\text { I opt: Optimal inc } \\
\text { Source PVGIS (c }\end{array}$ & $\begin{array}{l}\text { lorth, Longitude: } 3 \\
\text { eficit due to shadov } \\
\text { orizontal plane } \\
\text { a plane at } 11 \mathrm{deg} \\
\text { a plane at } 90 \mathrm{deg} \\
\text { ation. } \\
\text { uropean Communit }\end{array}$ & $\begin{array}{l}\text { 29" East, Optimal incl } \\
\text { g (horizontal): } 0 \%\end{array}$ & tion angle is: $11^{\circ}$ & \\
\hline
\end{tabular}

\subsubsection{Determining required number of modules}

In determining the number of modules to be used, the peak wattage of the array in $\mathrm{Wp}$ is divided by the product of the wattage of the module's maximum power tracking point and the temperature coefficient factor, as shown in (4) [9].

$n_{\text {mod }}=P_{\text {Array }} /\left(P_{M P P} \times T C F\right)$

where:

$n_{\text {mod }}=$ the total number of modules required to meet the expected load, and

$P_{M P P}=$ module wattage at MPPT mode $(\mathrm{W})$.

Determination of the number of modules in series or in parallel strictly depends on the voltage and current requirements on the system.

\subsection{Optimizer and inverter selection}

A suitable Optimizer typically a Buck-Boost Converter that can accept the range of DC output voltage from the PV Panel as input and give a specified DC output that goes into the inverted is selected. The inverter unit selection is made based on the voltage from the charge controller and the maximum power of AC load, about $20 \%$ higher than rated load is advisable [9]. A multi-string technology is preferred for this work.

\subsection{Optimizer and inverter selection}

Having selected all the components for the solar power plant, the Solar Photovoltaic computer software PVSYST version 6.43 was used to simulate the design. The software was developed initially by Dr. Andre Mermoud for the Group of Energy Institute of Science of the Environment, University of Geneva, 
Switzerland. Summary of the governing technical condition of the stand-alone system for the 3-MW and 4.8MW power plants are as presented in Table 3.

Table 3. General Data For 3-MW and 4.8-MW Stand-alone PV Plants

\begin{tabular}{|c|c|c|}
\hline \multicolumn{3}{|c|}{ Site resource/climate assessment } \\
\hline Latitude and longitude & \multicolumn{2}{|c|}{$\begin{array}{l}\text { nate assessment } \\
6^{\circ} 40^{\prime} 11^{\prime \prime} \text { North and } 3^{\circ} 9^{\prime} 14^{\prime \prime} \text { East }\end{array}$} \\
\hline Ambient air temperature & \multicolumn{2}{|c|}{$25.7^{\circ} \mathrm{C}$} \\
\hline Average wind speed & \multicolumn{2}{|l|}{$2.8 \mathrm{~m} / \mathrm{s}$} \\
\hline Average daily horizontal solar radiation & \multicolumn{2}{|l|}{$4.55 \mathrm{kWh} / \mathrm{m} 2 /$ day } \\
\hline Average sun hours (rainy season) & \multicolumn{2}{|l|}{4.0 hours } \\
\hline \multicolumn{3}{|c|}{ Technical Data } \\
\hline Plant size & $3 \mathrm{MW}$ & $4.8 \mathrm{MW}$ \\
\hline Designer/supervisor & \multicolumn{2}{|c|}{ Alabi Adeyemi A./Prof. A. U. Adoghe } \\
\hline Nominal capacity & $3,000 \mathrm{KW}$ & $4,800 \mathrm{KW}$ \\
\hline Operating temperature & $50{ }^{\circ} \mathrm{C}$ & \\
\hline Type of load & AC Load & \\
\hline Mode of generation & \multicolumn{2}{|c|}{ Decentralized } \\
\hline Current peak load & $2.55 \mathrm{MW}$ & $3.98 \mathrm{MW}$ \\
\hline Current base load (average) & $0.78 \mathrm{MW}$ & $0.79 \mathrm{MW}$ \\
\hline Reserve margin & $0.45 \mathrm{MW}$ & $0.82 \mathrm{MW}$ \\
\hline Total allotted land area & $20,499 \mathrm{~m}^{2}$ & $32,798 \mathrm{~m}^{2}$ \\
\hline Number of Modules & 12,600 & 20,160 \\
\hline PV array wattage per installed $\mathrm{KWp}$ & $3,150 \mathrm{KWp}$ & $5,040 \mathrm{kWp}$ \\
\hline Tilt angle & $11^{\circ}$ & $11^{0}$ \\
\hline Inverters & $7 \times 500 \mathrm{~kW}$ & $10 * 500 \mathrm{Kw}$ \\
\hline Conductor material & \multicolumn{2}{|c|}{ Copper } \\
\hline PV connection & \multicolumn{2}{|c|}{ Junction box } \\
\hline Cooling & \multicolumn{2}{|c|}{ Natural air cooling } \\
\hline \multicolumn{3}{|c|}{ Support Structure } \\
\hline Material & \multicolumn{2}{|c|}{ Steel } \\
\hline Coating & \multicolumn{2}{|c|}{ Galvanized } \\
\hline Tilt Angle & \multicolumn{2}{|c|}{$11^{\circ}$} \\
\hline Foundation & \multicolumn{2}{|c|}{ PCC (Plain cement concrete) } \\
\hline Type of tightening & \multicolumn{2}{|c|}{ Bolts, nuts and screws } \\
\hline \multicolumn{3}{|c|}{ Operation and Maintenance } \\
\hline PV modules cleaning & \multicolumn{2}{|c|}{ Once a month } \\
\hline Batteries routine maintenance & \multicolumn{2}{|c|}{ Once a week } \\
\hline Connection checking & \multicolumn{2}{|c|}{ Once a week } \\
\hline Safety measures & \multicolumn{2}{|c|}{ Lightening/surge protection } \\
\hline
\end{tabular}

\section{RESULTS AND ANALYSIS}

\subsection{Description of the designed 7.8-MW solar power plant}

The results obtained from the simulation of the of 3-MW and 4.8-MW Solar Power plant designs using the PV Syst Software Version 6.4.3 after inputting all necessary data are presented in this section. The Solar power plant is intended to supply power to meet the daytime load demand of the community. Power Generated from the solar plant will be sent to the local distribution control center in the community. During the day, preference is given to the generation from the solar po wer plant, expect for times when the power generated by the solar power plant will not be enough to meet the demand of the community; at these times, the first module of the 5 generators each rated 1.2-MW will supply energy in synchronization with the solar power to the community. Table 4 and Figure 1 show the block diagram and the table of design results for the solar plant.

Table 4. Specification of the Designed 3-MW and 4.8-MW, Solar Power Plant

\begin{tabular}{ccc}
\hline & $3 \mathrm{MW}$ & $4.8 \mathrm{MW}$ \\
\hline PV modules & 600 strings of 21 modules in series 12,600 total & 960 strings of 21 modules in series, 20,160 total \\
Pnom & $250 \mathrm{Wp}$ & $250 \mathrm{Wp}$ \\
Pnom array & $3,150 \mathrm{kWp}$ & $5,040 \mathrm{kWp}$ \\
Area & $20,499 \mathrm{~m}^{2}$ & $32,798 \mathrm{~m}^{2}$ \\
Inverters (500 kWac) & 7 units, Total 3,500 kWac & 10 units, Total 5,000 kWac \\
PNom Ratio & 0.807 & 0.807 \\
MPP Voltage & $30.7 \mathrm{~V}$ & $30.7 \mathrm{~V}$ \\
MPP Current & $8.1 \mathrm{~A}$ & $8.1 \mathrm{~A}$ \\
System Production & $4,172 \mathrm{MWh} / \mathrm{yr}$ & $6,673 \mathrm{MWh} / \mathrm{yr}$ \\
\hline
\end{tabular}




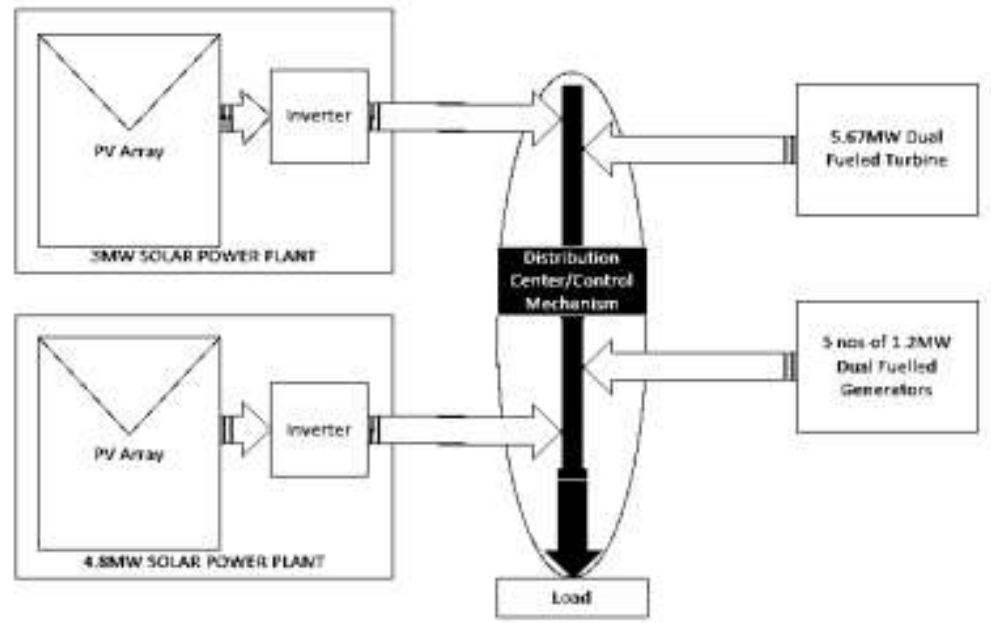

Figure 1. Block diagram description of the proposed design

\subsection{Comparison between the average power demanded and the average power generated by the 3 - MW, 4.8-MW and 7.8-MW PV system during the day time (7am-7pm)}

The simulation result of the daytime average power generated by the 3-MW, 4.8-MW and 7.8-MW systems from Pv Syst software was then compared with the daytime average power demanded by the respective communities. Figure 2, present a graph that plots the daytime peak and averaged power demanded by Covenant University and generated by the 3-MW plant. It can be observed from the Figure 2, that the solar power plant averagely begins to generate power at about 8am with an average power generation of $0.24 \mathrm{MW}$. This increases with the intensity of the solar irradiance to a peak of $2.27 \mathrm{MW}$ at $1 \mathrm{pm}$ when it then begins to drop as the sun sets back to as low as $0.03 \mathrm{MW}$ at $7 \mathrm{pm}$. The power demanded from Covenant University starts at $0.83 \mathrm{MW}$ at $8 \mathrm{am}$, demand at Covenant University peaks at 10am with a demand of $0.89 \mathrm{MW}$. The $3-\mathrm{MW}$ solar power plant will averagely cater for most of the average load demand by Covenant University between $8 \mathrm{am}$ and $5: 45 \mathrm{pm}$ and the peak generation from the 3-MW plant will sufficiently cater for the peak load demand between 10:30am and 4:30pm This means that during this period, the generators either do not need to come on or do not need to run at maximum.

Figure 3 presents a graph that plots the daytime peak and averaged power demanded by Covenant University and generated by the 4.8-MW plant. It can be observed from the Figure 3, that the solar power plant averagely begins to generate power at about $8 \mathrm{am}$ with an average power generation of $0.38-\mathrm{MW}$. The power generation peaks at $1 \mathrm{pm}$ with $3.63-\mathrm{MW}$, it then begins to drop as the sun sets back to as low as 0 .04MW at $7 \mathrm{pm}$. The power demanded from Mission starts at 0.91-MW at 8am; demand at Mission peaks at $11 \mathrm{am}$ with an average demand of 1.16-MW. The 4.8-MW solar power plant will averagely cater for most of the average load demand by Mission between 8:30am and $6 \mathrm{pm}$ and the peak generation from the 4.8-MW plant will sufficiently cater for the peak load demand between 10:15am and 4:30pm.

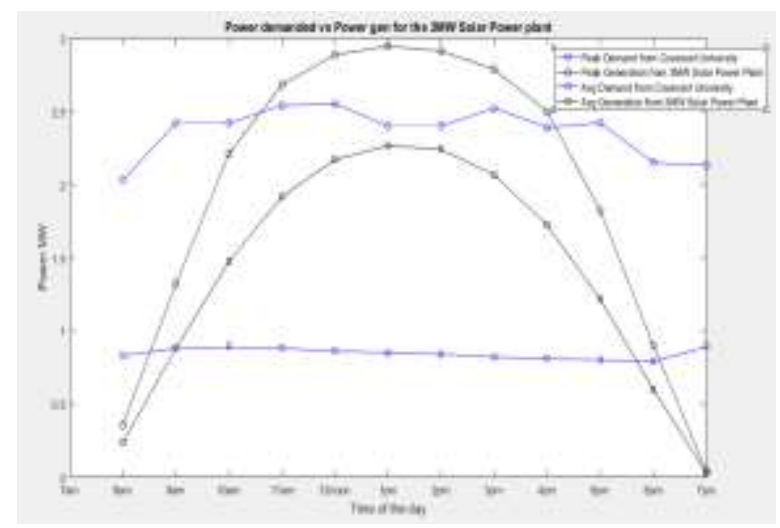

Figure 2. Daytime peak and average power demanded in Covenant University vs power generated by 3-MW solar power plant 


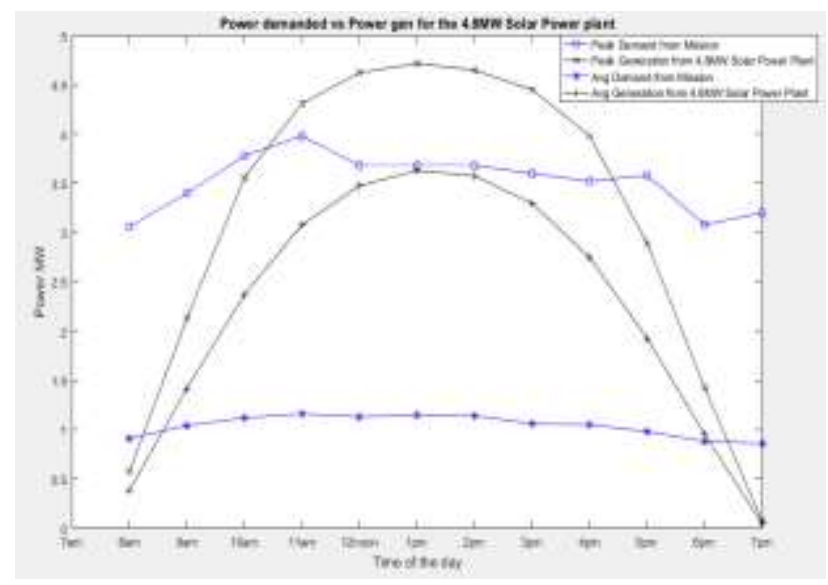

Figure 3. Daytime peak and average power in Canaanland vs power generated by 7.8-MW solar power plant

Figure 4 presents a graph that plots the daytime peak and averaged power demanded by Covenant University and generated by the 7.8-MW plant. It can be observed from the Figure 4, that the solar power plant averagely begins to generate power at about $8 \mathrm{am}$ with an average power generation of $0.62-\mathrm{MW}$, this increases with the intensity of the solar irradiance to a peak of 5.81-MW at $1 \mathrm{pm}$ when it then begins to drop as the sun sets back to as low as $0.07-\mathrm{MW}$ at $7 \mathrm{pm}$. The energy demanded from Canaanland starts at 1.74MW at 8am; demand at Mission peaks at $11 \mathrm{am}$ with an average demand of $2.04 \mathrm{MW}$. The 7.8-MW solar power plant will averagely cater for most of the average load demand by Mission between 8:30am and 6pm and the peak generation from the 7.8-MW plant will sufficiently cater for the peak load demand between 10:15am and 4:30pm.

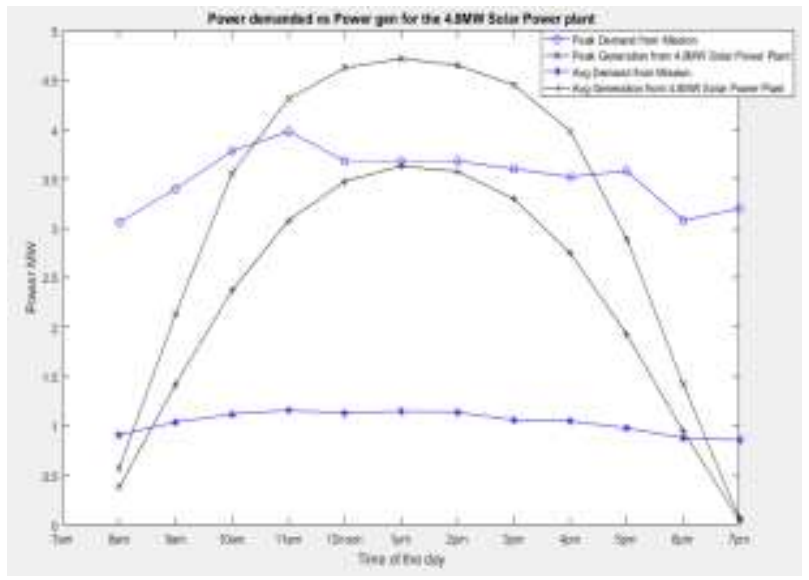

Figure 4. Daytime peak and average power demanded in Mission vs Power generated by 4.8-MW solar power plant

\subsection{Seasonal pattern comparison of daytime energy demanded by the community and energy supplied by the designed solar power plant}

The simulation result of the monthly daytime energy generated by the 3-MW, 4.8-MW and 7.8-MW systems from Pv Syst software was then compared with the monthly daytime energy demanded (7am- 7pm) by Covenant University, Mission and Canaanland. Result was plotted in Figures 5, 6 and 7 respectively, giving the opportunity to compare the monthly patterns of generation with the monthly load patterns. From Figure 5, It is observed that the period between May and November, which is usually the rainy season, power generation is relatively low. The daytime energy demanded by Covenant University between these months is equally low except in the month of September where the daytime energy demanded exceeds the average monthly power generated by the 3-MW power plant. In Figures 6 and 7 however, the averaged power generated by the 4.8-MW plant and the combined 7.8-MW Plant does meet the average daytime energy demand from Missions and Canaanland. 


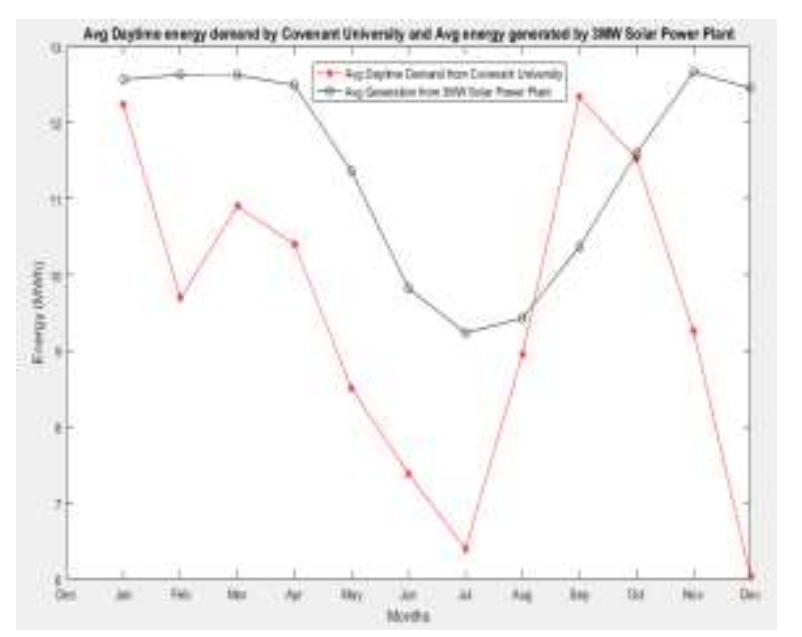

Figure 5. Average energy demand between $7 \mathrm{am}$ and $7 \mathrm{pm}$ every day for each month for Covenant University and Average power generated by 3-MW solar power plant

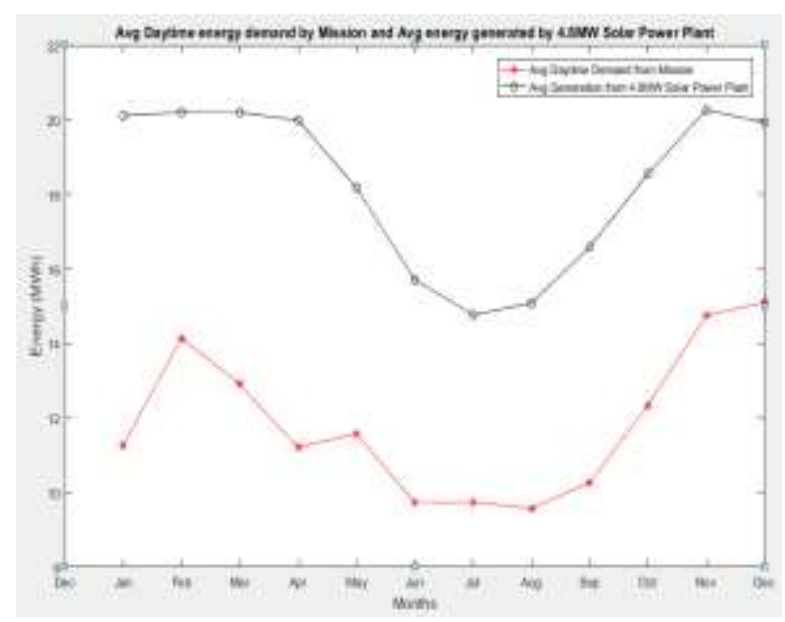

Figure 6. Average energy demand between $7 \mathrm{am}$ and $7 \mathrm{pm}$ every day for each month for mission and average power generated by $7.8-\mathrm{MW}$ solar power generated by $4.8-\mathrm{MW}$ solar power plant

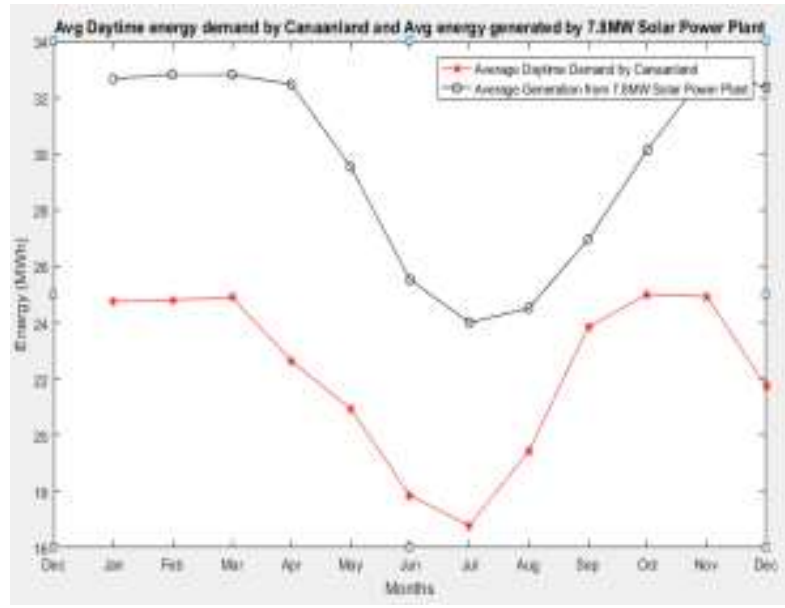

Figure 7. Average energy demand between $7 \mathrm{am}$ and $7 \mathrm{pm}$ every day for each month for Canaanland and Average power generated by 7.8-MW solar power 


\subsection{Investment cost}

The initial cost of the 3-MW and 4.8-MW Stand-Alone PV solar plants was estimated, Using the PVSyst software, the cost of the components uses in the design was fetched in their online repository and this revealed that an estimated cost of 5,140,277.78 US\$ is required as an investment cost for the project excluding other financing options through taxes, carbon credit financing and subsidies. A breakdown of the Estimated total investment cost is presented in Table 5.

Table 5. Estimated Project Investment Cost

\begin{tabular}{|c|c|c|c|c|c|c|}
\hline & & & 3-MW Solar PV & 4.8-MW Solar PV & 3-MW solar PV & 4.8-MW solar PV \\
\hline $\mathrm{S} / \mathrm{N}$ & Items & Amount (\$) & Units & Units & Total Cost (\$) & Total Cost (\$) \\
\hline 1 & PV Modules (250W) & 139 & 12,600 & 20,160 & $1,750,000.00$ & $2,800,000.00$ \\
\hline \multirow[t]{3}{*}{2} & Inverters (500kWac) & 34,722 & 7 & 10 & $243,055.56$ & $347,222.22$ \\
\hline & & & & Total & $1,993,055.56$ & $3,147,222.22$ \\
\hline & & & & Grand Total & & $5,140,277.78$ \\
\hline
\end{tabular}

\section{CONCLUSION}

The simulation result of the annual energy yield from the PV Syst software for the 3-MW System, is estimated to be $4,171,716 \mathrm{kWh}$; while the $4.8-\mathrm{MW}$ solar power plant is estimated to generate an annual energy yield of $6,673,038 \mathrm{kWh}$. The average annual daytime energy demand for Covenant University and Mission are $3,825,100 \mathrm{kWh}$, and $4,422,000 \mathrm{kWh}$ respectively. This leaves a reserve of $346,616 \mathrm{kWh}$ for Covenant University and 2,251,038kWh for Mission Estate. Combined together the average annual daytime energy demand for Canaanland is $8,247,100 \mathrm{kWh}$ while the combined annual yield by both solar power plant is estimated to be $10,844,754 \mathrm{kWh}$ leaving a reserve of $2,597,654 \mathrm{kWh}$. The result showed that the solar power plants designed will satisfactorily cater for energy demand of the community.

It was also shown that the solar power plants designed will be able to satisfy the daytime load demand of the community between 10:30am and 4:30pm throughout the year. During this period of the day, the community will be supplied power from the solar power plants. Allowing the existing generators in the community to be powered off, thereby reducing daily fuel consumption and cost. In the evening when the solar irradiance at the community has dropped, the generators will then be powered on to meet the demand of the community.

Results showed that for Mission Estate, the 4.8-MW solar power plant will cater for the entire daytime energy demand of the community round the year. While for Covenant University, the 3-MW solar power plant will cater for the entire daytime energy demand of the community for all months in the year except the months of September and October. This is because there is usually much rain during these periods, hence resulting in low irradiance because of the clouds. Also, the energy demanded by the community during these periods is usually higher due to the fact that the University resumes session at the ending August. However, when both power plants are combined, the Total energy demand of the whole Canaanland is met throughout the year.

\section{REFERENCES}

[1] S. O. Oyedepo, T. Adekeye, R. Leramo, O. Kilanko, and P. Babalola, "A Study on Energy Demand and Consumption in Covenant University, Ota, Nigeria," In: 2nd Covenant University Conference on African Development Issues (CU-ICADI), Nigeria, 2015.

[2] O. E. Abiodun and N. S. Segbenu, "Electricity End Use Characteristics of Public Universities in Southwestern Nigeria," British Journal of Environmental Sciences., vol. 5, no. 3, pp. 30-45, 2017.

[3] S. Rehman and L. M. Al-Hadhrami, "Study of a solar PV-diesel-battery hybrid power system for a remotely located population near Rafha, Saudi Arabia," Energy, vol. 35, no. 12, pp. 4986-4995, 2010.

[4] G. O. Unachukwu, "Energy savings opportunities at the University of Nigeria, Nsukka," J. Energy South. Africa, vol. 21, pp. 2-10, 2010.

[5] A. Babatunde and O. Olusola, "Regional Estimation of Solar Radiation using Routinal Meteorological Variables," Journal of Environment and Earth Science, vol. 5, no. 17, pp. 147-153, 2015.

[6] B. Isikwue, M. Akiishi, and E. Utah, "Investigation of the seasonal variations in the solar radiation balance and other solar energy parameters in some cities in Nigeria," Earth Science Research, vol. 3, no. 2, pp. 59-45, 2014.

[7] E. Babatunde, "Solar Energy, A Friendly Renewable Energy Option for Nigeria," Sol. Energy, A Friendly Renew. Energy option Niger., vol. 1, no. 15, 2007.

[8] H. Mitavachan, A. Gokhale, and J. Srinivasan, "3-MW scale grid-connected solar photovoltaic power plant at Kolar, Karnataka," 2011.

[9] C. Osueke, P. Uzendu, and I. Ogbonna, "Study and evaluation of solar enegry variation in Nigeria,"International Journal of Emerging Technology and Advanced Engineering, vol. 3, no. 6, pp. 501-505, 2013. 